\title{
Effects of audio and visual distraction on patients' vital signs and tolerance during esophagogastroduodenoscopy: a randomized controlled trial
}

Masahiro Sogabe ${ }^{1,2^{*}}$, Toshiya Okahisa ${ }^{1,2}$, Akira Fukuya ${ }^{1}$, Kaizo Kagemoto ${ }^{1}$, Yasuyuki Okada ${ }^{1}$, Yuka Adachi², Takeshi Kurihara ${ }^{2}$, Toru Nii ${ }^{2}$, Satoshi Teramae ${ }^{1}$, Hironori Tanaka ${ }^{1}$, Tetsu Tomonari ${ }^{1}$, Koichi Okamoto ${ }^{1}$, Hiroshi Miyamoto ${ }^{1}$, Masahiko Nakasono ${ }^{3}$ and Tetsuji Takayama ${ }^{1}$

\begin{abstract}
Background: Esophagogastroduodenoscopy (EGD) provides an indispensable and unambiguous inspection allowing the discovery upper gastrointestinal lesions. However, many patients are anxious about undergoing EGD. Few studies have investigated the influence on patients' vital signs and tolerance during EGD using subjective and objective assessments. This study was a prospective randomized controlled study that investigated the influence of audio and visual distraction on EGD.

Methods: We randomly divided 289 subjects who underwent EGD into 4 groups (control group, audio group, visual group, combination group) and examined their vital signs, heart rate variability (HRV), psychological items, and acceptance of distraction.

Results: Pulse rate (PR) at post-distraction and post-EGD in the 3 distraction groups were significantly lower than those of control group ( $p<0.001$ and $p<0.01$, respectively). Blood pressure (BP) during and post-EGD was significantly higher than that at pre-EGD in control group ( $p<0.05$ ), but no significant elevation of BP was observed during the latter half of EGD and post-EGD in the 3 distraction groups. BP at post-distraction improved significantly compared to pre-distraction in the 3 distraction groups $(p<0.05)$. There was a significant difference in the low-frequency (LF) power/ high-frequency (HF) power at post-distraction and post-EGD among the 4 groups $(p<0.001$ and $p<0.001$, respectively). The LF power/HF power at post-distraction and post-EGD in the 3 distraction groups was significantly lower than that in control group $(p<0.05)$. Several items of profile of mood states (POMS) and the impression of EGD at post-distraction improved significantly compared to those at pre-distraction among the 3 distraction groups $(p<0.05)$. Visual analog scale (VAS) of willingness for the next use of distraction in the 3 distraction groups was excellent because VAS was more than 70.

(Continued on next page)
\end{abstract}

\footnotetext{
* Correspondence: tokushimakenananshi@yahoo.co.jp

1 Department of Gastroenterology and Oncology, Tokushima University

Graduate School of Biomedical Sciences, 3-18-15 Kuramoto-cho, Tokushima city, Tokushima 770-8503, Japan

${ }^{2}$ Department of Internal Medicine, Shikoku Central Hospital of the Mutual aid Association of Public School teachers, Shikokuchuo, Japan

Full list of author information is available at the end of the article
}

(c) The Author(s). 2020 Open Access This article is licensed under a Creative Commons Attribution 4.0 International License, which permits use, sharing, adaptation, distribution and reproduction in any medium or format, as long as you give appropriate credit to the original author(s) and the source, provide a link to the Creative Commons licence, and indicate if changes were made. The images or other third party material in this article are included in the article's Creative Commons licence, unless indicated otherwise in a credit line to the material. If material is not included in the article's Creative Commons licence and your intended use is not permitted by statutory regulation or exceeds the permitted use, you will need to obtain permission directly from the copyright holder. To view a copy of this licence, visit http://creativecommons.org/licenses/by/4.0/. The Creative Commons Public Domain Dedication waiver (http://creativecommons.org/publicdomain/zero/1.0/) applies to the data made available in this article, unless otherwise stated in a credit line to the data. 
(Continued from previous page)

Conclusions: Distractions effectively improved psychological factors, vital signs and some of HRV at pre and post-EGD. Distractions may suppress BP elevation during the latter half of EGD and lead to stability of HRV on EGD.

Trial registration: This prospective trial was registered in the University Hospital Medical Information Network (UMIN) Clinical Trials Registry as UMIN000029637. Registered on 20 October 2017.

Keywords: Esophagogastroduodenoscopy, Vital signs, Heart rate variability, Distraction, Subjective and objective assessment

\section{Background}

Medical opportunities for the use of esophagogastroduodenoscopy (EGD) for the diagnosis of and therapy for etiology of gastrointestinal complaints and upper gastrointestinal cancer have increased. The development of smaller endoscope diameters reduced the unpleasant feeling and pain during EGD, but some person avoid undergoing EGD because of strong anxiety prior to the procedure [1-3]. Sedation increases the success rate of endoscopy and patient satisfaction during the endoscopic procedure [4-8], but sedation may increase the likelihood of complications, such as hypotension and respiratory depression [9-13]. Therefore, methods to improve patient anxiety during endoscopic examinations without sedation were examined. Several noninvasive intervention techniques, such as distraction using audio, visual, and olfactory stimulation, were introduced to decrease pain and anxiety during endoscopic examinations. Listening to music or watching images during various endoscopic procedures was an effective distraction in several reports, but most these reports used subjective assessments, such as pain, anxiety, and satisfaction [1, 14-16]. Few reports investigated the efficacy of the distraction of listening to music or watching images during EGD using a combination of subjective and objective assessments, including cardiovascular responses, heart rate variability (HRV), and a psychological questionnaire. We performed a prospective single-blind randomized controlled trial to assess the influence of distractions, such as audio and visual stimuli, during EGD.

\section{Methods}

\section{Study design}

This study protocol is included in additional Figure 1. This study was designed as a prospective, single-blinded randomized controlled trial, and it was performed at Shikoku Central Hospital of the Mutual Aid Association of Public School teachers. The Ethics Committee in Shikoku Central Hospital of the Mutual Aid Association of Public School teachers approved the study protocol, which was registered in the University Hospital Medical Information Network (UMIN Clinical Trials Registry, number UMIN000029637).

\section{Diagram of procedures and subject selection}

Figure 1 shows a flow diagram of the enrollment and procedures of this study. A total of 360 subjects were scheduled to receive EGD at a regular health check-up at our hospital participated in this study between October 2017 and March 2018. The study design was explained, and all subjects provided written informed consent. Seventy-one subjects were excluded from the study if they met any of the following criteria: (1) current medication use; (2) a history of severe heart failure, renal failure, hepatic failure, or chronic obstructive pulmonary disease; (3) previous abdominal surgery, including endoscopic mucosal resection (EMR) and endoscopic submucosal dissection (ESD); (4) audio or visual disability; (5) previous experience of bad feelings from audio or visual stimuli; (6) a history of anxiety or psychiatric disorders; (7) pregnant or a possibility of pregnancy; and (8) receiving a diagnosis of gastrointestinal cancer or required biopsy. Subjects presented to the endoscopy floor in the morning after a longer than 12-h fasting period. Subjects who was divided into two categories those underwent EGD for the first time and those experienced EGD previously and each subject was randomly divided into 4 groups using a sealed opaque numbered envelope method by the endoscopy nurse who assisted at EGD. All subjects sat on a sofa and rested quietly for $5 \mathrm{~min}$ in a private room near the endoscopy room. Subjects in control group continued to sit on the sofa and rest quietly for $10 \mathrm{~min}$ prior to EGD. Subjects in audio group sat on the sofa and listened to music for $10 \mathrm{~min}$. Subjects in visual group sat on the sofa and watched a silent natural image for $10 \mathrm{~min}$. Subjects in combination group sat on the sofa and watched a natural image while listening to music for $10 \mathrm{~min}$. The study used healing music, such as country and classical music, based on the tone of a music box, which was chosen as good by 20 volunteers in a pre-meeting prior to the start of this study. The moving images used in this study were various natural images, including a mountain, forest, river, waterfall, lake, and sunset. Music and natural images were delivered using a wall-type $\mathrm{Hi}$ vision liquid crystal television (TH-42AS650; Panasonic Corporation, Osaka, Japan). Pharyngeal anesthesia with lidocaine pump spray (Xylocaine Pump Spray 8\%; AstraZeneca, Osaka, Japan) without any sedative agents was 


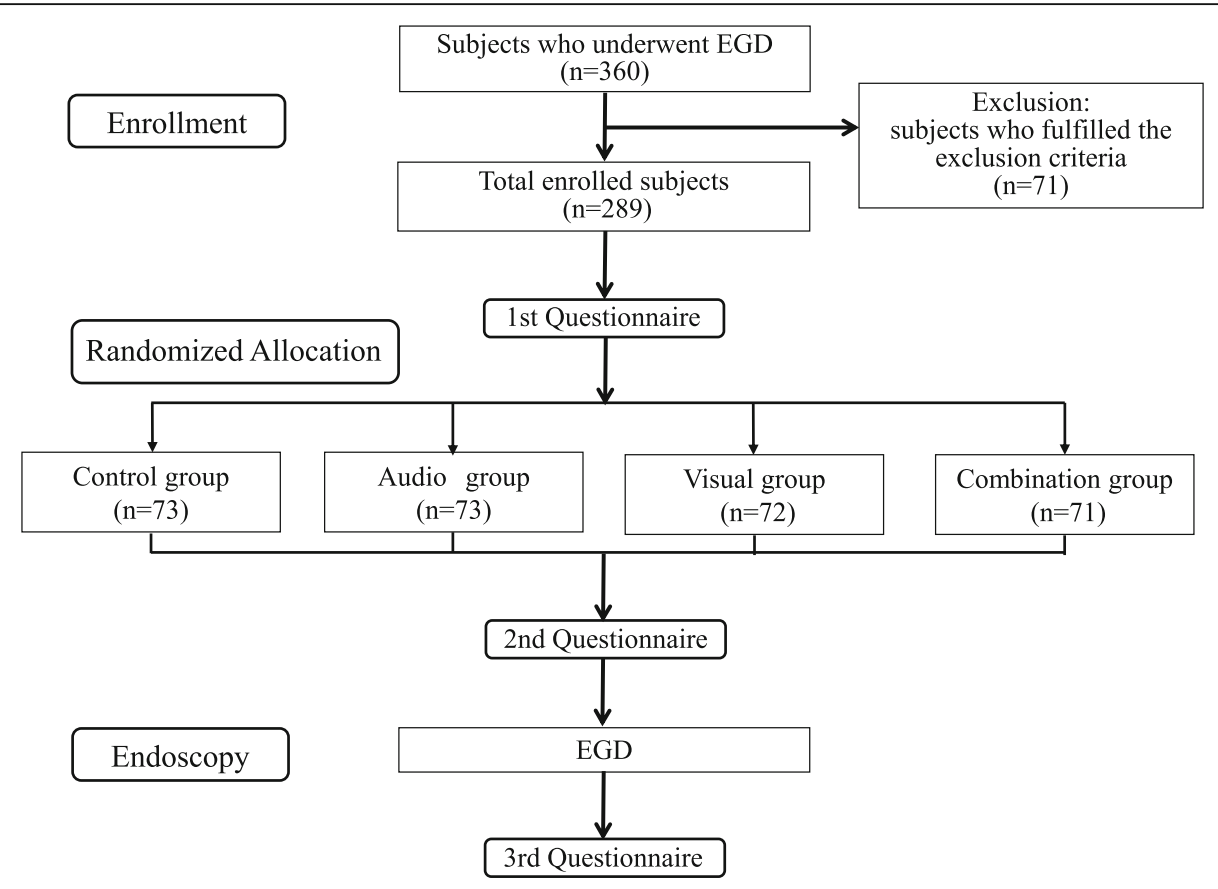

Fig. 1 CONSORT Diagram Showing the Flow of Participants through the Trial. EGD, esophagogastroduodenoscopy

applied, and 5 endoscopy specialists with greater than 5 years of experience in endoscopy performed a standard EGD, including observations of the esophagus, stomach, and duodenum, using a conventional single channel endoscope (GIF-H260; Olympus, Tokyo, Japan) without knowledge of the group of the subject. The profile of mood states (POMS) and the visual analog scale (VAS) of impressions for EGD were performed at pre- and post-distraction. VAS of the acceptance of distraction was performed after EGD.

\section{Measurement of vital signs}

Pulse rate (PR) and blood pressure (BP) were measured in the right upper arm, and peripheral blood oxygen saturation $\left(\mathrm{SpO}_{2}\right)$ was measured at the left finger using a monitor unit (BSM-7100 Life Scope; NIHON KOHDEN CORPORATION, Tokyo, Japan). These parameters were measured 5 and $15 \mathrm{~min}$ after sitting on the sofa, during EGD, and 5 min after EGD procedure. Parameters during EGD were measured just after insertion of the endoscope through the esophagogastric junction (approximately 2 min from the start of EGD) and just after moving the endoscope from the stomach to the esophagogastric junction (approximately 5-7 $\mathrm{min}$ from the start of EGD).

\section{Assessment of HRV}

We assessed autonomic nervous function from pre-EGD to post-EGD using power spectral analysis (PSA). HRV was measured using a Heart Rhythm Scanner (HRV analysis system from Biocom Technologies, Ark Trading
Pacific, Inc.) equipped with software that performed algorithms for short-term HRV analysis. A Biocom HRS08 Bluetooth Wireless Pulse Wave Sensor photoplethysmography monitor was used in this study, and it was clipped to the right earlobe. Data of the average R-R intervals for $5 \mathrm{~min}$ were subjected to PSA using the software of the HRV analysis system. The amplitudes of the low-frequency (LF) range (LF, $0.04-0.15 \mathrm{~Hz}$ ) and highfrequency $(\mathrm{HF})$ range $(\mathrm{HF}, 0.15-0.40 \mathrm{~Hz})$ were analyzed using complex demodulation. These LF and HF values were designated as the LF power and HF power, respectively. HF power is fluctuation in the heart rate caused by respiration, which is mediated by cardiac parasympathetic nervous activity $[17,18]$. The ratio of LF power to HF power is an index of sympathetic nervous activity [19-22]. The HF power data were converted to a logarithmic scale to analyze using linear regression in the present study.

\section{Psychological assessment and acceptance of distraction} We used the POMS2 questionnaire for psychological assessments between pre- and post-distraction because POMS is a self-report measure that quickly assesses transient, fluctuating feelings and enduring affective states [23, 24]. The POMS2 is composed of 35 items and 8 subscale scores. We also used the VAS, which consists of a $100-\mathrm{mm}$ horizontal line scored from 0 to 100 to rate the degrees of strain, anxiety, and fear of EGD. All subjects answered the POMS and provided their impressions of EGD immediately after sitting on the sofa and 
15 min after sitting on the sofa, but prior to EGD. After EGD, subject used the VAS to rate their degrees of satisfaction, usefulness, and willingness to assess the subject's acceptance of distraction.

\section{Outcomes}

The primary outcome measures were psychological factors including POMS and impression for EGD at postdistraction and acceptance of distraction including degrees of satisfaction, usefulness, and willingness for the next use at post EGD. The secondary outcome measures were vital signs, HRV at post-distraction, during EGD, and at post-EGD. Vital signs and HRV were measured at pre-EGD ( $5 \mathrm{~min}$ after sitting on the sofa), pre-EGD (15 min after sitting on the sofa), during the early and the latter half of EGD, and $5 \mathrm{~min}$ after the end of EGD.

\section{Statistical analysis}

We assumed that the appropriate sample size for the randomized subjects was over 180 subjects based on the requirement of a significant difference between 4 groups with a significance level of 0.05 , power of $80 \%$, and, effect size of 0.25 . Additionally, the rate of subjects who fill exclusion criteria or who received a diagnosis of gastrointestinal cancer or a biopsy was $30-40 \%$ by referring to our previous prospective randomized trial on endoscopy. Therefore, the planned required number of subject who receive EGD was over 300. Quantitative data, including subject characteristics, vital signs, POMS score, and VAS scores of impressions for EGD and acceptance of distraction, are expressed as the means \pm standard deviation (SD). Parameters of autonomic nervous function are expressed as the means \pm standard error of the mean (SEM). All significant differences at a $P$ value less than 0.05 were considered

Table 1 Baseline characteristics of subjects in the four groups

\begin{tabular}{|c|c|c|c|c|c|c|}
\hline & $\begin{array}{l}\text { Total subjects } \\
(\boldsymbol{n}=289)\end{array}$ & $\begin{array}{l}\text { Control } \\
\text { group } \\
(\boldsymbol{n}=73)\end{array}$ & $\begin{array}{l}\text { Audio } \\
\text { group } \\
(\boldsymbol{n}=73)\end{array}$ & $\begin{array}{l}\text { Visual } \\
\text { group } \\
(\boldsymbol{n}=72)\end{array}$ & $\begin{array}{l}\text { Combination } \\
\text { group } \\
(\boldsymbol{n}=71)\end{array}$ & $\boldsymbol{P}$-value \\
\hline Age (years) & $52.1 \pm 6.7$ & $52.8 \pm 6.7$ & $52.5 \pm 6.6$ & $50.7 \pm 7.3$ & $52.3 \pm 6.2$ & NS \\
\hline \multicolumn{7}{|l|}{ Gender } \\
\hline Male & 171 & 46 & 45 & 40 & 40 & \multirow[t]{2}{*}{ NS } \\
\hline Female & 118 & 27 & 28 & 32 & 31 & \\
\hline Smoking (+/-) & $35 / 254$ & $10 / 63$ & $9 / 64$ & $12 / 60$ & $4 / 67$ & NS \\
\hline Drinking (+/-) & $165 / 124$ & $45 / 28$ & $42 / 31$ & $40 / 32$ & $38 / 33$ & NS \\
\hline $\begin{array}{l}\text { Number of EGD } \\
\text { experience }\end{array}$ & $\begin{array}{l}4.3 \pm 3.4 \\
(0-20)\end{array}$ & $\begin{array}{l}4.4 \pm 3.9 \\
(0-20)\end{array}$ & $\begin{array}{l}4.5 \pm 3.8 \\
(0-16)\end{array}$ & $\begin{array}{l}4.1 \pm 2.6 \\
(0-11)\end{array}$ & $\begin{array}{l}4.4 \pm 3.3 \\
(0-15)\end{array}$ & NS \\
\hline Duration of EGD (sec) & $341 \pm 98$ & $330 \pm 96$ & $351 \pm 96$ & $355 \pm 116$ & $329 \pm 81$ & NS \\
\hline \multirow{2}{*}{\multicolumn{7}{|c|}{$\begin{array}{l}\text { First score of POMS } \\
\text { (negative mood) }\end{array}$}} \\
\hline & & & & & & \\
\hline $\mathrm{A}-\mathrm{H}$ & $46.5 \pm 7.5$ & $46.8 \pm 8.0$ & $46.2 \pm 6.9$ & $46.6 \pm 6.5$ & $46.3 \pm 8.3$ & NS \\
\hline C-B & $48.9 \pm 8.0$ & $48.4 \pm 8.5$ & $49.4 \pm 8.1$ & $49.6 \pm 7.2$ & $48.3 \pm 8.2$ & NS \\
\hline D-D & $48.9 \pm 7.2$ & $49.0 \pm 7.5$ & $49.8 \pm 8.2$ & $48.5 \pm 6.7$ & $48.5 \pm 6.3$ & NS \\
\hline F-I & $45.7 \pm 8.2$ & $46.0 \pm 9.6$ & $46.2 \pm 7.1$ & $45.3 \pm 7.1$ & $45.5 \pm 9.0$ & NS \\
\hline T-A & $52.3 \pm 9.8$ & $53.0 \pm 10.9$ & $50.9 \pm 8.6$ & $54.1 \pm 9.0$ & $51.4 \pm 10.5$ & NS \\
\hline TMD & $47.3 \pm 7.8$ & $48.0 \pm 9.0$ & $47.5 \pm 7.6$ & $47.6 \pm 6.7$ & $46.2 \pm 7.6$ & NS \\
\hline \multicolumn{7}{|l|}{ (positive mood) } \\
\hline V-V & $54.6 \pm 9.5$ & $54.4 \pm 10.6$ & $55.0 \pm 8.8$ & $55.3 \pm 9.1$ & $53.5 \pm 9.3$ & NS \\
\hline$F$ & $58.6 \pm 8.9$ & $56.8 \pm 9.7$ & $58.6 \pm 8.0$ & $59.2 \pm 8.7$ & $59.8 \pm 9.2$ & NS \\
\hline \multicolumn{7}{|l|}{$\begin{array}{l}\text { VAS of impression } \\
\text { for EGD }\end{array}$} \\
\hline Strain & $48.7 \pm 27.9$ & $46.6 \pm 26.7$ & $47.1 \pm 26.9$ & $53.7 \pm 27.9$ & $47.3 \pm 30.2$ & NS \\
\hline Anxiety & $40.3 \pm 27.7$ & $38.5 \pm 28.1$ & $44.5 \pm 26.8$ & $39.5 \pm 25.8$ & $38.8 \pm 30.0$ & NS \\
\hline Fear & $32.5 \pm 26.7$ & $29.6 \pm 25.3$ & $36.3 \pm 28.5$ & $32.3 \pm 23.2$ & $31.8 \pm 29.6$ & NS \\
\hline
\end{tabular}

$A-H$ Anger-hostility; C-B Confusion-bewilderment; $D-D$ Depression-dejection; EGD Esophagogastroduodenoscopy; $F$ friendship; F-I Fatigue-languid; POMS Profile of mood states; T-A Tension-anxiety; TMD Total mood distress; VAS Visual analog scale; $V$ - $V$ Vigor-vitality

Data represent the means \pm standard deviation (SD) and number for categorical variables. The $P$-value is based on the $m \times n X^{2}$ test or Kruskal Wallis test.

Significance is at the $5 \%$ level 


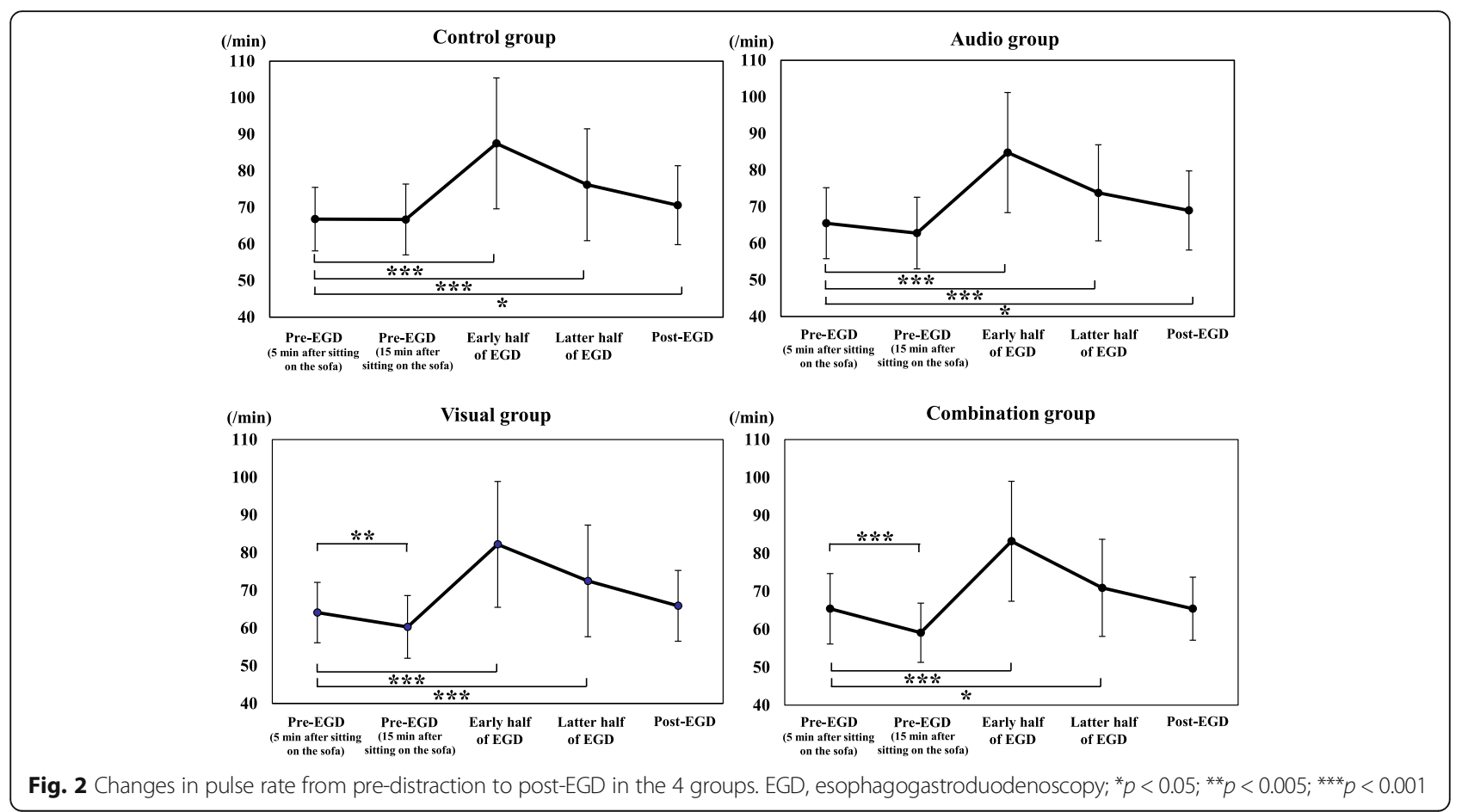

significant. The $\chi^{2}$-test or Mann-Whitney U-test was used for comparisons between 2 groups or pre- and post-distraction in same group. The $\mathrm{m} \times \mathrm{n} \mathrm{X}^{2}$-test or Kruskal Wallis test was used to analyze differences among 3 or 4 groups. If the Kruskal Wallis test revealed differences between the groups, then posthoc pairwise comparisons were performed using the Mann-Whitney U test with Bonferroni correction. All analyses were performed using Med Calc Software (Broekstraat, Mariakerke, Belgium).

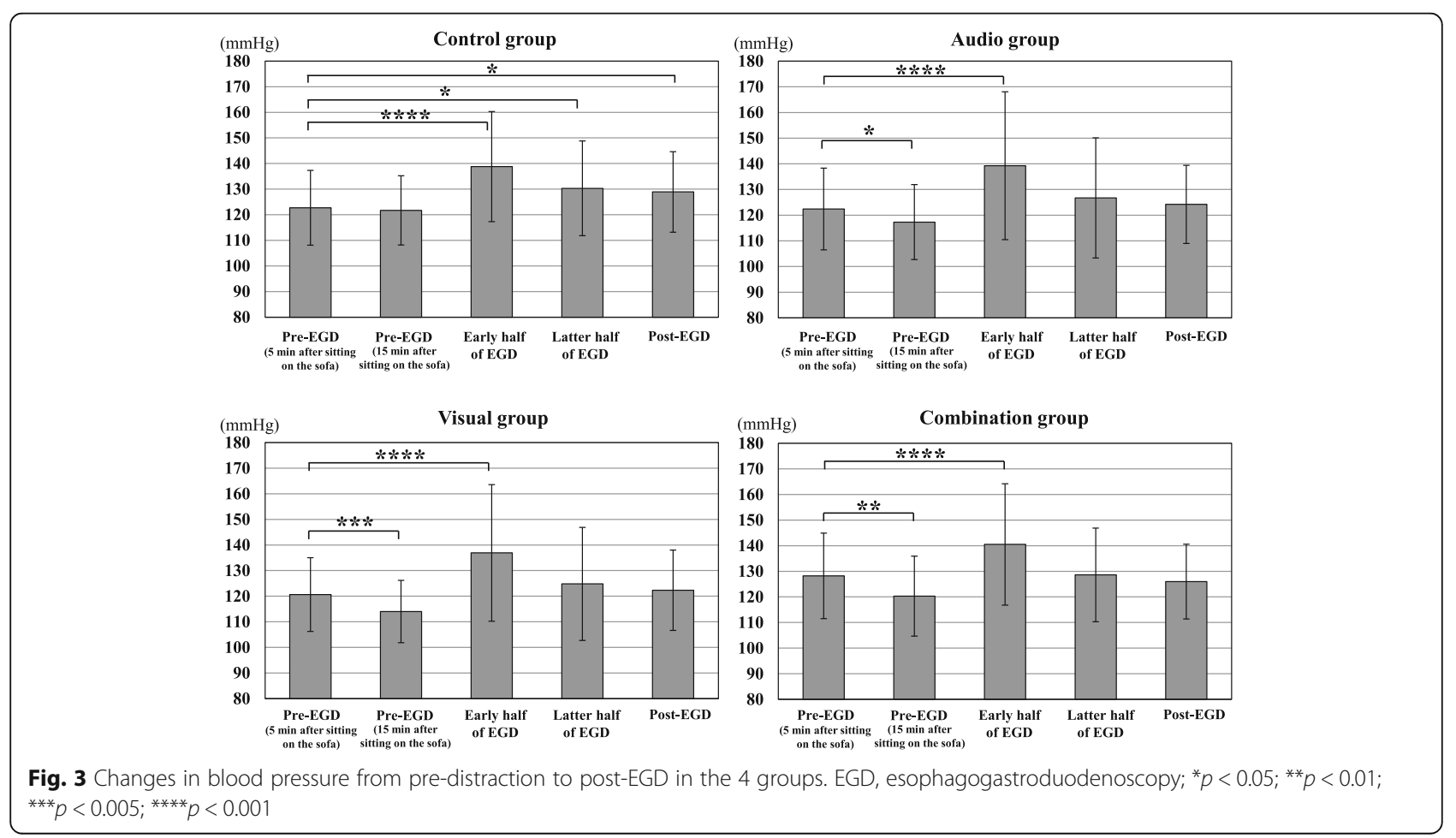



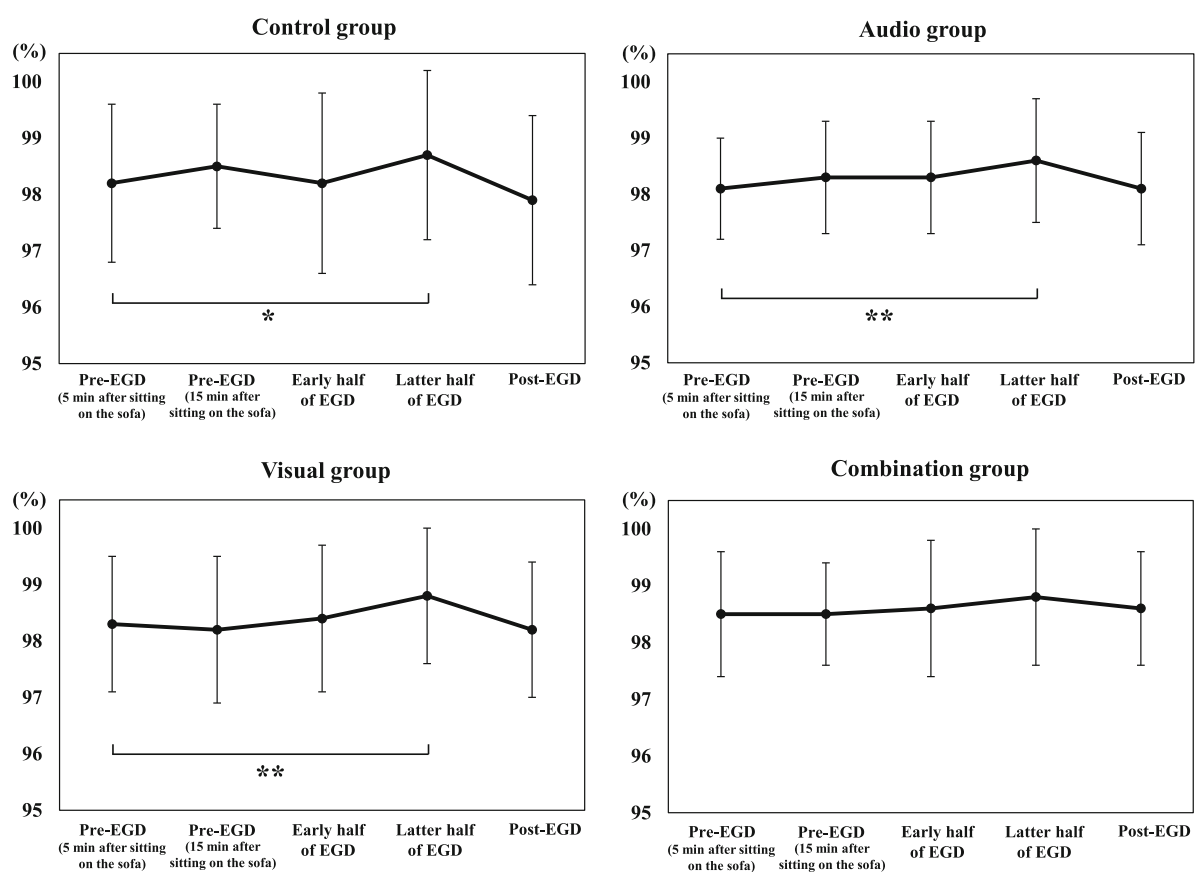

Fig. 4 Changes in blood oxygen saturation from pre-distraction to post-EGD in the 4 groups. EGD, esophagogastroduodenoscopy; ${ }^{*} p<0.01 ;{ }^{* *} p<0.005$

Table 2 Comparison of pulse rate at four points among the four groups

\begin{tabular}{|c|c|c|c|c|c|c|}
\hline & & Control group & Audio group & Visual group & $\begin{array}{l}\text { Combination } \\
\text { group }\end{array}$ & $P$-value \\
\hline \multirow{4}{*}{$\begin{array}{l}\text { Pre-EGD } \\
\text { ( } 5 \text { min after sitting on the sofa) (/min) }\end{array}$} & Mean & 66.8 & 65.5 & 64.1 & 65.4 & \multirow[t]{4}{*}{ NS } \\
\hline & SD & 8.7 & 9.7 & 8.0 & 9.3 & \\
\hline & Max & 49 & 45 & 44 & 42 & \\
\hline & Min & 93 & 92 & 87 & 87 & \\
\hline \multirow{4}{*}{$\begin{array}{l}\text { Pre-EGD } \\
\text { ( } 15 \text { min after sitting on the sofa) (/min) }\end{array}$} & Mean & $66.7 a$ & $62.8 b$ & $60.3 b c$ & $59.1 \mathrm{C}$ & \multirow[t]{4}{*}{$<0.001$} \\
\hline & SD & 9.7 & 9.8 & 8.3 & 7.8 & \\
\hline & Max & 95 & 94 & 85 & 80 & \\
\hline & Min & 47 & 43 & 42 & 40 & \\
\hline \multirow{4}{*}{$\begin{array}{l}\text { Early half of EGD } \\
\text { (/min) }\end{array}$} & Mean & 87.5 & 84.8 & 82.2 & 83.2 & \multirow[t]{4}{*}{ NS } \\
\hline & SD & 17.9 & 16.4 & 16.7 & 15.8 & \\
\hline & Max & 136 & 120 & 135 & 120 & \\
\hline & Min & 56 & 51 & 46 & 55 & \\
\hline \multirow{4}{*}{$\begin{array}{l}\text { Latter half of EGD } \\
\text { (/min) }\end{array}$} & Mean & 76.2 & 73.8 & 72.5 & 70.9 & \multirow[t]{4}{*}{ NS } \\
\hline & SD & 15.3 & 13.1 & 14.8 & 12.8 & \\
\hline & Max & 126 & 105 & 126 & 107 & \\
\hline & Min & 46 & 42 & 42 & 41 & \\
\hline \multirow{4}{*}{$\begin{array}{l}5 \text { min after the end of EGD } \\
\text { (/min) }\end{array}$} & Mean & $70.6 a$ & $69.0 \mathrm{~b}$ & $65.9 \mathrm{bc}$ & $65.4 c$ & \multirow[t]{4}{*}{$<0.01$} \\
\hline & SD & 10.8 & 10.8 & 9.4 & 8.3 & \\
\hline & Max & 103 & 95 & 90 & 85 & \\
\hline & Min & 50 & 45 & 44 & 40 & \\
\hline
\end{tabular}




\section{Results}

Baseline characteristics of subjects

Table 1 shows the baseline characteristics in the 4 groups. There was no significant difference in age, gender, smoking, drinking, experience or duration of EGD, POMS, and the impression for EGD among the 4 groups.

\section{Change in vital signs}

Figure 2 shows the changes in PR from pre-EGD to postEGD in the 4 groups. PRs during the early and the latter half of EGD, and $5 \mathrm{~min}$ after the end of EGD were significantly higher than pre-EGD ( $5 \mathrm{~min}$ after sitting on the sofa) in control group and audio group $(p<0.001$, $p<0.001$, and $p<0.05)$. PRs during the early and the latter half of EGD were significantly higher than pre-EGD (5 min after sitting on the sofa) in visual group $(p<0.001$ and $p<0.005)$ and combination group $(p<0.001$ and $p<0.05)$, but there was no significant difference in PR between pre-EGD ( $5 \mathrm{~min}$ after sitting on the sofa) and $5 \mathrm{~min}$ after the end of EGD, and PR at pre-EGD (15 min after sitting on the sofa) was significantly lower than pre-EGD (5 min after sitting on the sofa) in visual group $(p<0.005)$ and combination group $(p<0.001)$.
Figure 3 shows the changes in BP from pre-EGD to post-EGD in the 4 groups. BPs during the early and the latter half of EGD, and $5 \mathrm{~min}$ after the end of EGD were significantly higher than pre-EGD (5 min after sitting on the sofa) in control group $(p<0.001$, $p<0.05$, and $p<0.05)$. BP during the early half of EGD was significantly higher than pre-EGD (5 min after sitting on the sofa) in the 3 distraction groups $(p<0.001)$, but no significant BP elevation was observed during the latter half of EGD and $5 \mathrm{~min}$ after the end of EGD. BP at pre-EGD (15 min after sitting on the sofa) was significantly lower than pre-EGD (5 min after sitting on the sofa) in the 3 distraction groups $(p<0.05)$.

Fig. 4 shows the changes in $\mathrm{SpO}_{2}$ from pre-EGD to post-EGD in the 4 groups. $\mathrm{SpO}_{2}$ during the latter half of EGD was significantly higher than pre-EGD (5 min after sitting on the sofa) in control group, audio group, and visual group $(p<0.01, p<0.005$, and $p<0.005)$.

\section{Comparison of PR at each point}

Table 2 shows a comparison of PR at each point among the 4 groups. There was no significant difference in PR

Table 3 Comparison of blood pressure at four points among the four groups

\begin{tabular}{|c|c|c|c|c|c|c|}
\hline & & $\begin{array}{l}\text { Control } \\
\text { group }\end{array}$ & $\begin{array}{l}\text { Audio } \\
\text { group }\end{array}$ & $\begin{array}{l}\text { Visual } \\
\text { group }\end{array}$ & $\begin{array}{l}\text { Combination } \\
\text { group }\end{array}$ & $P$-value \\
\hline \multirow{4}{*}{$\begin{array}{l}\text { Pre-EGD } \\
\text { ( } 5 \text { min after sitting on the sofa) ( } \mathrm{mmHg} \text { ) }\end{array}$} & Mean & 122.8 & 122.4 & 120.6 & 128.3 & \multirow[t]{4}{*}{ NS } \\
\hline & SD & 14.6 & 15.9 & 14.4 & 16.7 & \\
\hline & Max & 157 & 161 & 157 & 178 & \\
\hline & Min & 96 & 90 & 91 & 97 & \\
\hline \multirow{4}{*}{$\begin{array}{l}\text { Pre-EGD } \\
\text { (15 min after sitting on the sofa) }(\mathrm{mmHg})\end{array}$} & Mean & $121.7 \mathrm{~b}$ & 117.3 & $114.0 \mathrm{a}$ & $120.3 b$ & \multirow[t]{4}{*}{$<0.005$} \\
\hline & SD & 13.5 & 14.6 & 12.2 & 15.6 & \\
\hline & Max & 158 & 156 & 158 & 171 & \\
\hline & Min & 98 & 90 & 89 & 90 & \\
\hline \multirow{4}{*}{$\begin{array}{l}\text { Early half of EGD } \\
\text { (mmHg) }\end{array}$} & Mean & 138.8 & 139.3 & 136.9 & 140.5 & \multirow[t]{4}{*}{ NS } \\
\hline & SD & 21.5 & 28.8 & 26.7 & 23.7 & \\
\hline & Max & 188 & 214 & 224 & 200 & \\
\hline & Min & 91 & 88 & 87 & 79 & \\
\hline \multirow{4}{*}{$\begin{array}{l}\text { Latter half of EGD } \\
\text { (mmHg) }\end{array}$} & Mean & 130.3 & 126.7 & 124.8 & 128.6 & \multirow[t]{4}{*}{ NS } \\
\hline & SD & 18.5 & 23.4 & 22.1 & 18.3 & \\
\hline & Max & 180 & 195 & 194 & 171 & \\
\hline & Min & 93 & 88 & 90 & 78 & \\
\hline \multirow{4}{*}{$\begin{array}{l}5 \mathrm{~min} \text { after the end of EGD } \\
(\mathrm{mmHg})\end{array}$} & Mean & $128.9 a$ & 124.2 & $122.3 b$ & 126.0 & \multirow[t]{4}{*}{$<0.05$} \\
\hline & SD & 15.7 & 15.2 & 15.7 & 14.6 & \\
\hline & Max & 193 & 164 & 182 & 166 & \\
\hline & Min & 97 & 92 & 96 & 100 & \\
\hline
\end{tabular}

EGD Esophagogastroduodenoscopy; SD Standard deviation

The $P$-value is based on the Kruskal Wallis test. Significance is at the $5 \%$ level. Post hoc pairwise comparisons were performed using the Mann-Whitney $U$ test with Bonferroni correction. Different letters indicate a significant difference at the $0.00833(0.05 / 6)$ level 
at pre-EGD ( $5 \mathrm{~min}$ after sitting on the sofa), during the early half of EGD, and the latter half of EGD among the 4 groups. However, there was a significant difference in PR at pre-EGD (15 min after sitting on the sofa) and 5 min after the end of EGD among the 4 groups on the Kruskal Wallis test $(p<0.001$ and $p<0.01)$. Post-hoc pairwise comparisons revealed that PRs at pre-EGD (15 min after sitting on the sofa) and 5 min after the end of EGD in the 3 distraction groups were significantly lower than control group.

\section{Comparison of BP at each point}

Table 3 shows a comparison of $\mathrm{BP}$ at each point among the 4 groups. There was no significant difference in $\mathrm{BP}$ at pre-EGD ( $5 \mathrm{~min}$ after sitting on the sofa), during the early half of EGD, and the latter half of EGD among the 4 groups. However, there was a significant difference in BP at pre-EGD (15 min after sitting on the sofa) and $5 \mathrm{~min}$ after the end of EGD among the 4 groups on the Kruskal Wallis test $(p<0.005$ and $p<0.05)$. Post-hoc pairwise comparisons revealed that BP at pre-EGD ( $15 \mathrm{~min}$ after sitting on the sofa) and 5 min after the end of EGD in visual group was significantly lower than control group.

\section{Comparison of $\mathrm{SpO}_{2}$ at each point}

Table 4 shows a comparison of $\mathrm{SpO}_{2}$ at each point among the 4 groups. There was no significant difference in $\mathrm{SpO}_{2}$ at pre-EGD (5 min after sitting on the sofa), pre-EGD (15 min after sitting on the sofa), during the early half of EGD, and the latter half of EGD among the 4 groups. However, there was a significant difference in $\mathrm{SpO}_{2}$ at $5 \mathrm{~min}$ after the end of EGD among the 4 groups on the Kruskal Wallis test $(p<0.01)$. Post-hoc pairwise comparisons revealed that $\mathrm{SpO}_{2}$ at 5 min after the end of EGD in combination group were significantly higher than control group.

\section{Changes in HRV}

Figure 5-A shows a comparison of Log HF power from pre-EGD to post-EGD among the 4 groups. There was a significant difference in Log HF power during the early and the latter half of EGD, and 5 min after the end of EGD among the 4 groups on the Kruskal Wallis test $(p<0.001, p<0.01$, and $p<0.05)$. Post-hoc pairwise comparisons revealed that Log HF powers during the early half of EGD in the 3 distraction groups was significantly higher than control group.

Table 4 Comparison of blood oxygen saturation at four points among the four groups

\begin{tabular}{|c|c|c|c|c|c|c|}
\hline & & $\begin{array}{l}\text { Control } \\
\text { group }\end{array}$ & $\begin{array}{l}\text { Audio } \\
\text { group }\end{array}$ & $\begin{array}{l}\text { Visual } \\
\text { group }\end{array}$ & $\begin{array}{l}\text { Combination } \\
\text { group }\end{array}$ & $P$-value \\
\hline \multirow{4}{*}{$\begin{array}{l}\text { Pre-EGD } \\
\text { ( } 5 \text { min after sitting on the sofa) (\%) }\end{array}$} & Mean & 98.2 & 98.1 & 98.3 & 98.5 & \multirow[t]{4}{*}{ NS } \\
\hline & SD & 1.4 & 0.9 & 1.2 & 1.1 & \\
\hline & Max & 100 & 100 & 100 & 100 & \\
\hline & Min & 93 & 95 & 94 & 96 & \\
\hline \multirow{4}{*}{$\begin{array}{l}\text { Pre-EGD } \\
\text { (15 min after sitting on the sofa) (\%) }\end{array}$} & Mean & 98.5 & 98.3 & 98.2 & 98.5 & \multirow[t]{4}{*}{ NS } \\
\hline & SD & 1.1 & 1.0 & 1.3 & 0.9 & \\
\hline & Max & 100 & 100 & 100 & 100 & \\
\hline & Min & 95 & 96 & 94 & 96 & \\
\hline \multirow[t]{4}{*}{ Early half of EGD (\%) } & Mean & 98.2 & 98.3 & 98.4 & 98.6 & \multirow[t]{4}{*}{ NS } \\
\hline & SD & 1.6 & 1.0 & 1.3 & 1.2 & \\
\hline & Max & 100 & 100 & 100 & 100 & \\
\hline & Min & 91 & 95 & 93 & 95 & \\
\hline \multirow[t]{4}{*}{ Latter half of EGD (\%) } & Mean & 98.7 & 98.6 & 98.8 & 98.8 & \multirow[t]{4}{*}{ NS } \\
\hline & SD & 1.5 & 1.1 & 1.2 & 1.2 & \\
\hline & Max & 100 & 100 & 100 & 100 & \\
\hline & Min & 92 & 96 & 95 & 95 & \\
\hline \multirow[t]{4}{*}{5 min after the end of EGD (\%) } & Mean & $97.9 \mathrm{~b}$ & $98.1 b$ & 98.2 & $98.6 a$ & \multirow[t]{4}{*}{$<0.01$} \\
\hline & SD & 1.5 & 1.0 & 1.2 & 1.0 & \\
\hline & Max & 100 & 100 & 100 & 100 & \\
\hline & Min & 94 & 96 & 95 & 95 & \\
\hline
\end{tabular}

EGD Esophagogastroduodenoscopy; SD Standard deviation

The $P$-value is based on the Kruskal Wallis test. Significance is at the $5 \%$ level. Post hoc pairwise comparisons were performed using the Mann-Whitney $U$ test with Bonferroni correction. Different letters indicate a significant difference at the $0.00833(0.05 / 6)$ level 

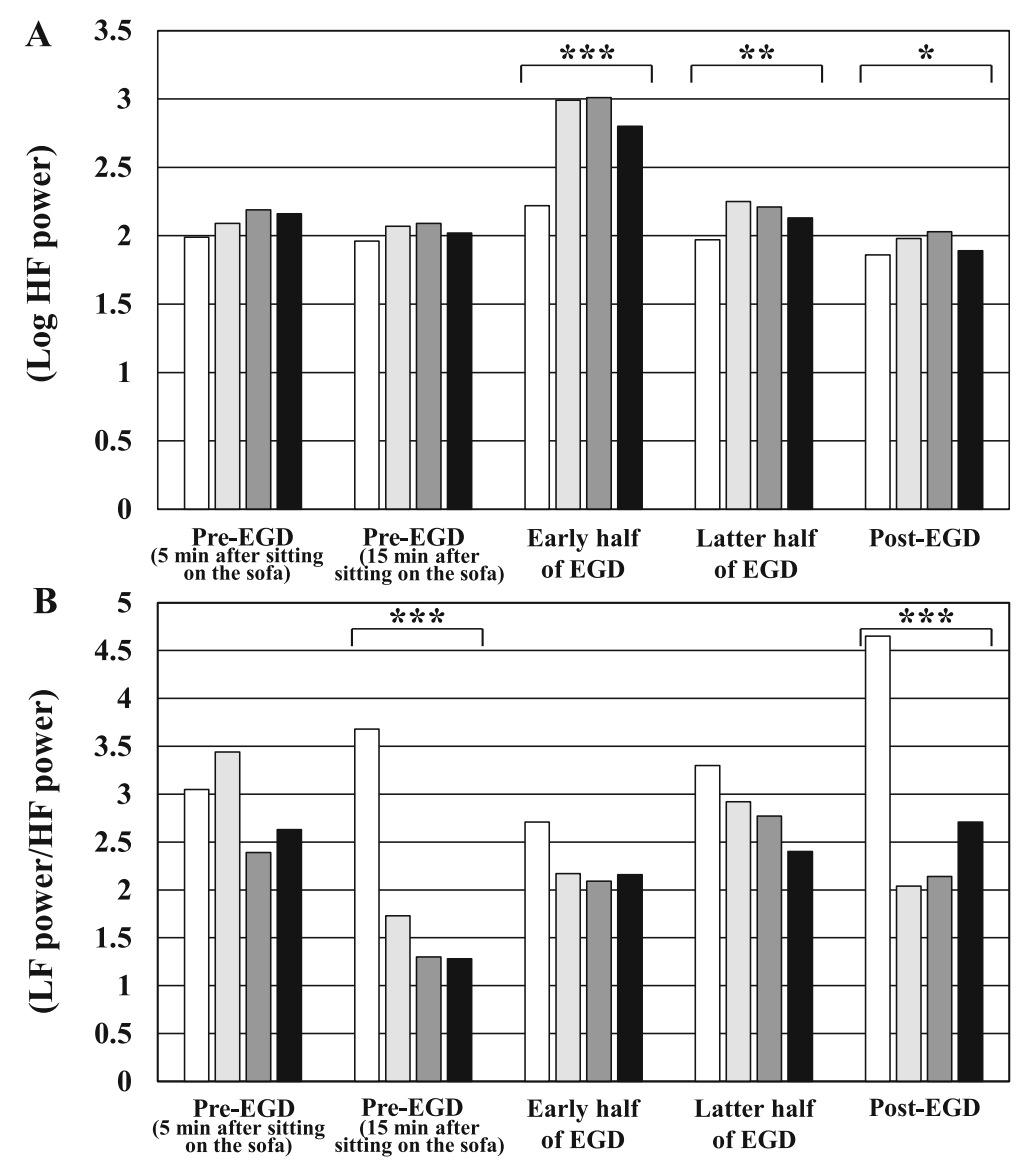

Fig. 5 Changes in heart rate variability from pre-EGD to post-EGD in the 4 groups. a Comparisons of Log HF powers from pre-EGD to post-EGD in the 4 groups. $\mathbf{b}$ Comparisons of LF power/ HF power from pre-EGD to post-EGD in the 4 groups. The white bar indicates the values of control group. The light gray bar indicates values of audio group. The dark gray bar indicates values of visual group. The black bar indicates values of combination group. EGD, esophagogastroduodenoscopy; HF, high frequency; LF, low frequency; ${ }^{*} P<0.05 ;{ }^{* *} P<0.01$; ${ }^{* * *} P<0.001$

Figure 5-B shows a comparison of LF power/ HF power from pre-EGD to post-EGD between the 4 groups. There was a significant difference in LF power/ HF power at pre-EGD (15 min after sitting on the sofa) and 5 min after the end of EGD among the 4 groups on the Kruskal Wallis test $(p<0.001$ and $p<0.001)$. Posthoc pairwise comparisons revealed that LF power/ HF power at pre-EGD (15 min after sitting on the sofa) and 5 min after the end of EGD in the 3 distraction groups was significantly lower than control group.

\section{Influence of distraction on POMS and the impression for EGD}

Table 5 shows a comparison of POMS and the impression for EGD between pre- and post-distraction in the 3 distraction groups. The score for negative mood at postdistraction was significantly lower than at pre-distraction in the 3 distraction groups $(p<0.05)$. The VAS scores of strain, anxiety, and fear for EGD at post-distraction were significantly lower than pre-distraction in audio group $(p<0.05, p<0.05$, and NS), visual group $(p<0.005$, NS, and NS), and combination group $(p<0.001, p<0.05$, and $p<0.05)$.

\section{Acceptance of distraction after EGD}

Table 6 shows a comparison of the acceptance of the distraction after EGD among the 3 distraction groups.

There was a significant difference in usefulness of the distraction and satisfaction of the distraction among the 3 groups on the Kruskal Wallis test $(p<0.005)$. Posthoc pairwise comparisons revealed that the usefulness of the distraction and the satisfaction of the distraction in combination group was significantly higher than visual group. Although there was no significant difference in willingness for the next use of the distraction among the 3 groups, the degree of willingness for the next use of the distraction was excellent because the VAS was more than 70 in the 3 groups.

\section{Discussion}

Several studies examined the benefits of audio and video distraction during various endoscopy procedures 
Table 5 Comparison of POMS and the impression for EGD between pre- and post-distraction in the three distraction groups

\begin{tabular}{|c|c|c|c|c|}
\hline Group & POMS and impression for EGD & Pre-distraction & Post-distraction & $P$-value \\
\hline \multirow{14}{*}{$\begin{array}{l}\text { Audio } \\
\text { group }\end{array}$} & (POMS: Score of negative mood) & & & \\
\hline & $\mathrm{A}-\mathrm{H}$ & $46.2 \pm 6.9$ & $44.1 \pm 6.9$ & $<0.05$ \\
\hline & C-B & $49.4 \pm 8.1$ & $46.8 \pm 7.8$ & $<0.05$ \\
\hline & $D-D$ & $49.8 \pm 8.2$ & $47.3 \pm 7.3$ & $<0.05$ \\
\hline & $\mathrm{F}-\mathrm{I}$ & $46.2 \pm 7.1$ & $43.2 \pm 7.6$ & $<0.01$ \\
\hline & T-A & $50.9 \pm 8.6$ & $46.0 \pm 9.2$ & $<0.001$ \\
\hline & TMD & $47.5 \pm 7.6$ & $43.9 \pm 7.7$ & $<0.005$ \\
\hline & (POMS: Score of positive mood) & & & \\
\hline & $V-V$ & $55.0 \pm 8.8$ & $55.4 \pm 9.4$ & NS \\
\hline & $\mathrm{F}$ & $58.6 \pm 8.0$ & $58.6 \pm 9.8$ & NS \\
\hline & (VAS of impression for EGD) & & & \\
\hline & Strain & $47.1 \pm 26.9$ & $37.5 \pm 23.9$ & $<0.05$ \\
\hline & Anxiety & $44.5 \pm 26.8$ & $34.3 \pm 25.4$ & $<0.05$ \\
\hline & Fear & $36.3 \pm 28.5$ & $27.3 \pm 25.2$ & NS \\
\hline \multirow{14}{*}{$\begin{array}{l}\text { Visual } \\
\text { group }\end{array}$} & (POMS: Score of negative mood) & & & \\
\hline & $\mathrm{A}-\mathrm{H}$ & $46.6 \pm 6.5$ & $44.3 \pm 6.9$ & $<0.05$ \\
\hline & C-B & $49.6 \pm 7.2$ & $46.6 \pm 7.0$ & $<0.005$ \\
\hline & D-D & $48.5 \pm 6.7$ & $46.0 \pm 5.9$ & $<0.005$ \\
\hline & $\mathrm{F}-\mathrm{I}$ & $45.3 \pm 7.1$ & $42.5 \pm 6.4$ & $<0.01$ \\
\hline & T-A & $54.1 \pm 9.0$ & $47.2 \pm 7.9$ & $<0.001$ \\
\hline & TMD & $47.6 \pm 6.7$ & $43.7 \pm 6.3$ & $<0.001$ \\
\hline & (POMS: Score of positive mood) & & & \\
\hline & $V-V$ & $55.3 \pm 9.1$ & $54.4 \pm 11.1$ & NS \\
\hline & $\mathrm{F}$ & $59.2 \pm 8.7$ & $58.6 \pm 10.5$ & NS \\
\hline & (VAS of impression for EGD) & & & \\
\hline & Strain & $53.7 \pm 27.9$ & $40.5 \pm 22.0$ & $<0.005$ \\
\hline & Anxiety & $39.5 \pm 25.8$ & $34.9 \pm 24.4$ & NS \\
\hline & Fear & $32.3 \pm 23.2$ & $31.0 \pm 26.7$ & NS \\
\hline \multirow{14}{*}{$\begin{array}{l}\text { Combination } \\
\text { group }\end{array}$} & (POMS: Score of negative mood) & & & \\
\hline & $\mathrm{A}-\mathrm{H}$ & $46.3 \pm 8.3$ & $42.6 \pm 6.8$ & $<0.001$ \\
\hline & C-B & $48.3 \pm 8.2$ & $44.9 \pm 6.7$ & $<0.005$ \\
\hline & D-D & $48.5 \pm 6.3$ & $45.1 \pm 5.9$ & $<0.001$ \\
\hline & $\mathrm{F}-\mathrm{I}$ & $45.5 \pm 9.0$ & $40.5 \pm 6.5$ & $<0.001$ \\
\hline & T-A & $51.4 \pm 10.5$ & $43.9 \pm 8.4$ & $<0.001$ \\
\hline & TMD & $46.2 \pm 7.6$ & $42.2 \pm 6.6$ & $<0.001$ \\
\hline & (POMS: Score of positive mood) & & & \\
\hline & $V-V$ & $53.5 \pm 9.3$ & $53.7 \pm 10.9$ & NS \\
\hline & $\mathrm{F}$ & $59.8 \pm 9.2$ & $59.8 \pm 10.5$ & NS \\
\hline & (VAS of impression for EGD) & & & \\
\hline & Strain & $47.3 \pm 30.2$ & $28.3 \pm 25.9$ & $<0.001$ \\
\hline & Anxiety & $38.9 \pm 30.0$ & $27.6 \pm 26.2$ & $<0.05$ \\
\hline & Fear & $31.8 \pm 29.6$ & $22.6 \pm 26.5$ & $<0.05$ \\
\hline
\end{tabular}

$A-H$ Anger-hostility; $C-B$ Confusion-bewilderment; $D-D$ Depression-dejection; EGD Esophagogastroduodenoscopy; $F$ Friendship; F-I Fatigue-languid; POMS Profile of mood states; T-A Tension-anxiety; TMD Total mood distress; VAS Visual analog scale; $V$ - $V$ Vigor-vitality 
Table 6 Comparison of the acceptance of the distraction after EGD among the three distraction groups

\begin{tabular}{|c|c|c|c|c|}
\hline & $\begin{array}{l}\text { Audio } \\
\text { group }\end{array}$ & $\begin{array}{l}\text { Visual } \\
\text { group }\end{array}$ & Combination group & $P$-value \\
\hline $\begin{array}{l}\text { Usefulness } \\
\text { of the distraction }\end{array}$ & $72.3 \pm 16.5$ & $67.7 \pm 15.5 a$ & $76.4 \pm 17.4_{b}$ & $<0.005$ \\
\hline $\begin{array}{l}\text { Satisfaction } \\
\text { of the distraction }\end{array}$ & $68.6 \pm 19.4$ & $64.2 \pm 18.6_{a}$ & $74.0 \pm 18.6_{b}$ & $<0.005$ \\
\hline $\begin{array}{l}\text { Willingness for the next } \\
\text { use of distraction }\end{array}$ & $76.4 \pm 17.3$ & $73.1 \pm 20.3$ & $78.1 \pm 17.7$ & NS \\
\hline
\end{tabular}

EGD Esophagogastroduodenoscopy

Data represent the means \pm standard deviation (SD)

The $P$-value is based on the Kruskal Wallis-test. Significance is at the $5 \%$ level. Post hoc pairwise comparisons were performed using the Mann-Whitney $U$ test with Bonferroni correction. Different letters indicate a significant difference at the $0.01667(0.05 / 3)$ level

[1, 14-16, 25-31]. However, no clear recommendations for distraction were established because assessments in previous reports were based solely on subjective items, such as tolerance, pain, anxiety and satisfaction. To our knowledge, this is the first study evaluating the influence of distractions on EGD using subjective and objective measures.

The incidence of gastric cancer decreased worldwide in recent decades, but it remains a major cause of cancerrelated mortality [32]. Therefore, EGD is an indispensable instrument to discover upper gastrointestinal cancer and perform endoscopic treatments, such as EMR and ESD. Appropriate methods for amount and use of sedation, improved techniques and apparatus for endoscopy were established. However, serious complications related to endoscopic procedures and sedation remain and are a problematic. The exact mechanisms of these complications remain conjectural, but the importance of vital sign changes and causes related to the autonomic nerve system were demonstrated. There were several reports of an association with endoscopy procedure and the autonomic nervous system, but few reports associated EGD and distractions using objective assessments, such as vital signs and autonomic nervous function [33, 34].

The present study demonstrated that BP at postdistraction (i.e., immediately pre-EGD) in the distraction groups improved significantly, but no improvement in $\mathrm{BP}$ was observed in the no distraction group. BP during and post-EGD increased significantly in the no distraction group, but no significant BP elevation was observed during the latter half of EGD and post-EGD in the distraction groups. There was also no significant elevation in $\mathrm{PR}$ at post-EGD in visual group, and combination group. These results suggest that distraction suppresses vital sign elevation at pre-EGD, during a portion of EGD, and at post-EGD.

There was a significant difference in Log HF power during the early half of EGD between the control group and distraction groups. The vomiting reflex affects the early half of EGD because of endoscope insertion. Additionally, gastrointestinal distention by air supply from the top of endoscopy may induce activation of a vagal reflex $[35,36]$. Promotion of parasympathetic nervous activity may be induced by not only the influence of distraction but also vomiting reflex and gastrointestinal distention because of stimulation of endoscope insertion.

The LF power/HF power ratios at post-distraction (i.e., immediately pre-EGD) and post-EGD in the distraction groups were significantly lower than control group. These results suggest that distraction inhibited activity of sympathetic nervous function.

The psychological influence of music or visual distraction on endoscopy procedures remains controversial, but the number of articles reporting positive effects on anxiety levels appears slightly greater than negative effects articles [1, 14-16, 25-31, 37]. The present study demonstrated that the scores for negative mood based on POMS and impression of EGD at post-distraction (immediately pre-EGD) improved significantly compared to the baseline condition in the distraction groups. Acceptance of distraction in all distraction groups was relatively good.

The present study had some limitations that should be noted. First, we used healing music and natural images that were selected as good by 20 volunteers in a premeeting for the selection of music prior to the start of the present study. However, whether the music and images used in this study were the more suitable for each subject is not clear. Second, different results may occur between persons who underwent EGD for the first time and persons who experienced EGD previously. Further investigation of subjects who undergo EGD for the first time or comparisons between persons who undergo EGD for the first time and repeated procedures is required. Last, there was a possibility of selection bias because all of the participants in the present study were healthy individuals undergoing a medical check-up. The mean of age of the subjects was relatively young. Whether sick persons or elderly populations would produce similar results to the present study is not clear. Further studies are necessary to resolve these limitations. 


\section{Conclusions}

The present study demonstrated that distractions effectively improved psychological factors, vital signs, and HRV at pre and post-EGD. Additionally, distractions suppressed BP elevations during the latter half of EGD and sympathetic nerve function elevation at post-EGD. Although it is important for persons to undergo EGD to discover gastrointestinal lesions, the necessity for improvements in various physical and psychological conditions at pre-EGD should be considered.

\section{Supplementary information}

Supplementary information accompanies this paper at https://doi.org/10. 1186/s12876-020-01274-3.

Additional file 1: Figure 1. This study protocol. BP, blood pressure; EGD, esophagogastroduodenoscopy; HF, high-frequency; HRV, heart rate variability; LF, low-frequency; POMS, profile of mood states; PR, pulse rate.

\section{Abbreviations}

BP: Blood pressure; EGD: Esophagogastroduodenoscopy; HF: High-frequency; HRV: Heart rate variability; LF: Low-frequency; POMS: Profile of mood states; PR: Pulse rate; PSA: Power spectral analysis; VAS: Visual analog scale

\section{Acknowledgments \\ The authors would like to thank all subjects in our study. Additionally, the authors would like to thank all endoscopy nurses, the former hospital director (Masaharu Kamata), and the hospital director (Tetsuya Kitagawa) at Shikoku Central Hospital of the Mutual aid Association of Public School teachers.}

\section{Authors' contributions}

MS: study concept and design, data collection, statistical analysis, and writing of the draft manuscript, $\mathrm{HM}$ and MN: study co-design, AF, KK, YO, YA, and KO: endoscopy, TA, TN, and ST: data collection and data analysis, TK, HT and $\Pi T 1$ : data collection and visualization, TO and TT2: study co-design and review of the manuscript. All authors have approved the final version of the article.

\section{Funding}

None.

\section{Availability of data and materials}

The datasets used and analyzed during the current study will be available from the corresponding author on reasonable request.

\section{Ethics approval and consent to participate}

Written informed consent was obtained from all subjects. The study protocol was approved by the Ethics Committee in Shikoku Central Hospital of the Mutual Aid Association of Public School teachers and this study was performed in accordance with the Declaration of Helsinki. This trial was registered in the University Hospital Medical Information Network (UMIN) Clinical Trials Registry as UMIN000029637.

\section{Consent for publication}

Not applicable.

\section{Competing interests}

The authors declare that they have no competing interests.

\section{Author details}

'Department of Gastroenterology and Oncology, Tokushima University Graduate School of Biomedical Sciences, 3-18-15 Kuramoto-cho, Tokushima city, Tokushima 770-8503, Japan. ${ }^{2}$ Department of Internal Medicine, Shikoku Central Hospital of the Mutual aid Association of Public School teachers,
Shikokuchuo, Japan. ${ }^{3}$ Department of Internal Medicine, Tsurugi Municipal Handa Hospital, Tsurugi, Japan.

Received: 9 July 2019 Accepted: 13 April 2020

Published online: 21 April 2020

\section{References}

1. El-Hassan H, McKeown K, Muller AF. Clinical trial: music reduces anxiety levels in patients attending for endoscopy. Aliment Pharmacol Ther. 2009; 30:718-24.

2. Brandt L. Patients' attitudes and apprehensions about endoscopy: how to calm troubled waters. Am J Gastroenterol. 2001;96:280-4.

3. Johnson JE, Morrissey JF, Leventhal H. Psychological preparation for an endoscopic examination. Gastrointest Endosc. 1973;19:180-1.

4. Keeffe EB, O'Connor KW. 1989 a/S/G/E survey of endoscopic sedation and monitoring practices. Gastrointest Endosc. 1990;36:S13-8.

5. Froehlich F, Gonvers JJ, Fried M. Conscious sedation, clinically relevant complications and monitoring of endoscopy: results of a nationwide survey in Switzerland. Endoscopy. 1994;26:231-4.

6. Abraham NS, Fallone CA, Mayrand S, Huang J, Wieczorek P, Barkun AN. Sedation versus no sedation in the performance of diagnostic upper gastrointestinal endoscopy: a Canadian randomized controlled costoutcome study. Am J Gastroenterol. 2004;99:1692-9.

7. Cohen LB, Delegge MH, Aisenberg J, Brill JV, Inadomi JM, Kochman ML, et al. AGA Institute review of endoscopic sedation. Gastroenterology. 2007; 133:675-701.

8. McQuaid KR, Laine L. A systematic review and meta-analysis of randomized, controlled trials of moderate sedation for routine endoscopic procedures. Gastrointest Endosc. 2008;67:910-23.

9. Bell GD. Preparation, premedication, and surveillance. Endoscopy. 2004;36: $23-31$.

10. Holm C, Christensen M, Rasmussen V, Schulze S, Rosenberg J. Hypoxaemia and myocardial ischaemia during colonoscopy. Scand J Gastroenterol. 1998; 33:769-72.

11. Nelson DB, Barkun AN, Block KP, Burdick JS, Ginsberg GG, Greenwald DA, et al. Propofol use during gastrointestinal endoscopy. Gastrointest Endosc. 2001;53:876-9.

12. Ko CW, Riffle S, Michaels L, Morris C, Holub J, Shapiro JA, et al. Serious complications within 30 days of screening and surveillance colonoscopy are uncommon. Clin Gastroenterol Hepatol. 2010;8:166-73.

13. Lee SY, Son HJ, Lee JM, Bae MH, Kim JJ, Paik SW, et al. Identification of factors that influence conscious sedation in gastrointestinal endoscopy. J Korean Med Sci. 2004;19:536-40.

14. Lee DW, Chan KW, Poon CM, Ko CW, Chan KH, Sin KS, et al. Relaxation music decreases the dose of patientcontrolled sedation during colonoscopy: a prospective randomized controlled trial. Gastrointest Endosc 2002;55:33-6.

15. Lembo T, Fitzgerald L, Matin K, Woo K, Mayer EA, Naliboff BD. Audio and visual stimulation reduces patient discomfort during screening flexible sigmoidoscopy. Am J Gastroenterol. 1998:93:1113-6.

16. Lee DW, Chan AC, Wong SK, Fung TM, Li AC, Chan SK, et al. Can visual distraction decrease the dose of patient-controlled sedation required during colonoscopy? A prospective randomized controlled trial. Endoscopy. 2004; 36:197-201.

17. Hayano J, Sakakibara Y, Yamada A, Yamada M, Mukai S, Fujinami T, et al. Accuracy of assessment of cardiac vagal tone by heart rate variability in normal subjects. Am J Cardiol. 1991;67:199-204.

18. Pagani M, Lombardi F, Guzzetti S, Rimoldi O, Furlan R, Pizzinelli P, et al. Power spectral analysis of heart rate and arterial pressure variabilities as a marker of sympatho-vagal interaction in man and conscious dog. Circ Res. 1986:59:178-93.

19. Pomeranz B, Macaulay RJ, Caudill MA, Kutz I, Adam D, Gordon D, et al. Assessment of autonomic function in humans by heart rate spectral analysis. Am J Phys. 1985;248:H151-3.

20. Akselrod S, Gordon D, Ubel FA, Shannon DC, Berger AC, Cohen RJ. Power spectrum analysis of heart rate fluctuation: a quantitative probe of beat-tobeat cardiovascular control. Science. 1981;213:220-2.

21. Malliani A, Pagani M, Lombardi F, Cerutti S. Cardiovascular neural regulation explored in the frequency domain. Circulation. 1991;84:482-92.

22. Task force of the European Society of Cardiology and the North American Society of Pacing and Electrophysiology. Heart rate variability. Standards of 
measurement, physiological interpretation, and clinical use. Circulation. 1996;93:1043-65.

23. Kanbara K, Fukunaga M, Mutsuura H, Takeuchi H, Kitamura K, Nakai Y. An exploratory study of subgrouping of patients with functional somatic syndrome based on the psychophysiological stress response: its relationship with moods and subjective variables. Psychosom Med. 2007;69:158-65.

24. Terry PC, Lane AM, Lane HJ, Keohane L. Development and validation of a mood measure for adolescents. J Sports Sci. 1999;17:861-72.

25. Ovayolu N, Ucan O, Pehlivan S, Pehlivan Y, Buyukhatipoglu H, Savas MC, et al. Listening to Turkish classical music decreases patients' anxiety, pain, dissatisfaction and the dose of sedative and analgesic drugs during colonoscopy: a prospective randomized controlled trial. World J Gastroenterol. 2006;12:7532-6.

26. López-Cepero Andrada JM, Amaya Vidal A, Castro Aguilar-Tablada T, García Reina I, Silva L, Ruiz Guinaldo A, et al. Anxiety during the performance of colonoscopies: modification using music therapy. Eur I Gastroenterol Hepatol. 2004;16:1381-6.

27. Chlan L, Evans D, Greenleaf M, Walker J. Effects of a single music therapy intervention on anxiety, discomfort, satisfaction, and compliance with screening guidelines in outpatients undergoing flexible sigmoidoscopy. Gastroenterol Nurs. 2000;23:148-56.

28. Palakanis KC, DeNobile JW, Sweeney WB, Blankenship CL. Effect of music therapy on state anxiety in patients undergoing flexible sigmoidoscopy. Dis Colon Rectum. 1994;37:478-81.

29. Hayes A, Buffum M, Lanier E, Rodahl E, Sasso C. A music intervention to reduce anxiety prior to gastrointestinal procedures. Gastroenterol Nurs. 2003;26:145-9.

30. Danhauer SC, Marler B, Rutherford CA, Lovato JF, Asbury DY, McQuellon RP, et al. Music or guided imagery for women undergoing colposcopy: a randomized controlled study of effects on anxiety, perceived pain, and patient satisfaction. J Low Genit Tract Dis. 2007;11:39-45.

31. Colt HG, Powers A, Shanks TG. Effect of music on state anxiety scores in patients undergoing fiberoptic bronchoscopy. Chest. 1999;116:819-24.

32. Siegel R, Naishadham D, Jemal A. Cancer statistics, 2013. CA Cancer J Clin. 2013;63:11-30

33. Mori A, Ohashi N, Tatebe H, Maruyama T, Inoue H, Takegoshi S, et al. Autonomic nervous function in upper gastrointestinal endoscopy: a prospective randomized comparison between transnasal and oral procedures. J Gastroenterol. 2008:43:38-44.

34. Kataoka H, Hayano J, Mizushima T, Tanaka M, Kubota E, Shimura T, et al. Cardiovascular tolerance and autonomic nervous responses in unsedated upper gastrointestinal small-caliber endoscopy: a comparison between transnasal and peroral procedures with newly developed mouthpiece. Dig Endosc. 2011;23:78-85.

35. Andrews PL, Grundy D, Scratcherd T. Vagal afferent discharge from mechanoreceptors in different regions of the ferret stomach. J Physiol. 1980; 298:513-24.

36. Zhang $X$, Jiang $C$, Tan Z, Fogel R. Vagal motor neurons in rats respond to noxious and physiological gastrointestinal distention differentially. Eur J Neurosci. 2002;16:2027-38.

37. Umezawa S, Higurashi T, Uchiyama S, Sakai E, Ohkubo H, Endo H, et al. Visual distraction alone for the improvement of colonoscopy-related pain and satisfaction. World J Gastroenterol. 2015;21:4707-14.

\section{Publisher's Note}

Springer Nature remains neutral with regard to jurisdictional claims in published maps and institutional affiliations.

Ready to submit your research? Choose BMC and benefit from:

- fast, convenient online submission

- thorough peer review by experienced researchers in your field

- rapid publication on acceptance

- support for research data, including large and complex data types

- gold Open Access which fosters wider collaboration and increased citations

- maximum visibility for your research: over $100 \mathrm{M}$ website views per year

At BMC, research is always in progress.

Learn more biomedcentral.com/submissions 